\title{
Wood: A Modern Material?
}

\author{
Roger M Rowell* \\ Department of Biological Systems Engineering, University of Wisconsin, USA
}

*Corresponding author: Roger M Rowell, Professor Emeritus, Department of Biological Systems Engineering, University of Wisconsin, Madison, WI, USA.
Received Date: August 01, 2020

Published Date: August 12, 2020

\begin{abstract}
It is possible to produce biobased materials from wood that are consistent, uniform, predictable, and reproduceable. Reducing wood to fiber eliminates natural defects present in solid wood. The fiber can be modified with simple chemistry to add durability and stability properties.
\end{abstract}

Keywords: Wood; Fiber; Moisture; Stability; Durability; Acetylation

\section{Introduction}

Many articles are written predicting that wood will be the sustainable building material for the future. This is not accurate as wood is not a material. A tree is renewable and sustainable and in order to ensure a continuous supply of wood, management of forest lands should be under a proactive system of land management whose goal is both sustainable forestry and the promotion of healthy ecosystems. We also say that wood was designed by Nature as a building material. This is also not true. Wood was designed to perform wet, so it is flexible to bend in the wind. We cut the wet tree down, dry it and use it for products that are durable. Also, not true. Wood was designed to degrade back to $\mathrm{CO}_{2}$ and water through five basic chemistries-Oxidation, Hydrolysis, Reduction, Free Radical, Dehydration. Can you imagine what the world would look like if wood did not decay?

We refer to wood as a material. A definition of a material is that it is consistent, uniform, predictable and reproduceable. No two pieces of wood are alike even if they come from the same tree, the same board or within a board. Wood also swells and shrinks with changing moisture and is attacked by decay fungi. So, it is also not stable or durable.
So, if wood is to be considered as a future building "material", how can we convert wood to a modern material that is consistent, uniform, predictable, reproduceable, stable and durable? The object of this research is to answer that question.

\section{Background}

As solid wood is broken down into smaller and smaller units (chips, particles, fiber), it becomes more uniform as the defects (knots, splits, juvenile, reaction, etc.) are removed/blended. When wood is reduced to fiber, it becomes very uniform. Since many forests now contain an excess of small diameter mixed tree species, these can be used to produce fiber that can be used to produce what we can call "biomaterials".

The fiber can be made into composite products that are consistent, uniform, predictable and reproducible but not stable or durable. Stability and durability can be achieved by modifying the fiber by reacting the fiber with acetic anhydride (acetylation). Acetylation of wood has been shown to greatly improve both stability and durability [1].

Acetylation is a simple chemical reaction with a cell wall polymer hydroxyl group and acetic anhydride. The reaction takes place 
in the most accessible hydroxyl groups and is a single-addition reaction, which means that one acetyl group is on one hydroxyl group with no polymerization. Thus, all the weight gain in acetyl can be directly converted into units of hydroxyl groups blocked.

WOOD-OH $+\mathrm{CH}_{3}-\mathrm{C}(=\mathrm{O})-\mathrm{O}-\mathrm{C}(\mathrm{C}=0)-\mathrm{CH}_{3}$ (Acetic anhydride $) \rightarrow$ WOOD-O-C(=0)- $\mathrm{CH}_{3}$ (Acetylated wood) $+\mathrm{CH}_{3}-\mathrm{C}(=\mathrm{O})-\mathrm{OH}$ (Acetic acid)

The purpose of the present research is to present methods to breakdown wood into fiber, and to apply a known chemical modification acetylation process to increase stability and durability.

\section{Materials and Methods}

Southern yellow pine lumber, with a moisture content of approximately $40 \%$, was run through an industrial chipper to produce chips. The chips were then run through either an atmospheric Asplund Defibrator D connected to a $20 \mathrm{hp} \mathrm{Baldor} \mathrm{Industrial} \mathrm{motor}$ or placed under pressure in a laboratory scale Masonite exploder located in West Chicago, IL and the pressure quickly released to atmospheric pressure causing the chips to explode into fiber bundles and single fibers. The fibers were then dried in a forced dryer overnight at $105^{\circ} \mathrm{C}$.

Oven dried southern yellow pine fiber was reacted with acetic anhydride in a stainless-steel reactor for 4 hours at $120^{\circ} \mathrm{C}$. The reaction liquid was removed, the fiber washed in cold water and dried at $105^{\circ} \mathrm{C}$ overnight. Oven dried southern yellow pine wood $2.5 \times 2.5 \times 0.6 \mathrm{~cm}$, (radial x tangential x longitudinal) was reacted with acetic anhydride at $120^{\circ} \mathrm{C}$ in a in a stainless-steel reactor for 4 hours at $120^{\circ} \mathrm{C}$. The reaction liquid was removed, the wood washed in cold water and dried at $105^{\circ} \mathrm{C}$ overnight. Acetyl content was determined using gas chromatography according to the procedure outlined in Beckers et al. [2].

Equilibrium moisture content (EMC) was determined on oven-dry control and acetylated sold wood and fiber placed in constant humidity room at $90 \%$ relative humidity (RH) and $27^{\circ} \mathrm{C}$. After 21 days the specimens were weighed to determine the EMC.
The ASTM D 1413 standard soil block test was performed on solid wood blocks and on compressed fiber cubes $\left(1.9 \mathrm{~cm}^{3}\right)$ [3]. Untreated controls and acetylated wood and fiber were exposed to the brown-rot fungus Gloeophyllum trabeum or the white-rot fungi Trametes versicolor. Specimens were removed from test after 12 weeks and dried. The extent of decay was determined as oven dry weight loss.

\section{Results and Discussion}

Table 1 shows the acetyl content and equilibrium moisture content of southern pine wood and fiber. Southern yellow pine contains 0.8 to 1.9 acetyl naturally. There is a slightly higher EMC for the Masonite fiber as compared to the Asplund fiber. This may be due to the higher lignin content on the surface of the Asplund fiber since in this process the chips are heat softened and the fibers tend to slip apart as opposed to the Masonite process where the chips are broken/exploded apart resulting in more carbohydrate on the surface of the fibers.

Fiber-based composites have been made using acetylated fiber and have very high dimensional stability. Acetylation has bulked the fiber cell wall back to its green dimension so further swelling cannot take place without exceeding the cell wall elastic limit.

Table 2 shows the results of the ASTM D 1413 standard soil block test. The brown-rot fungus destroyed both the solid wood and the fiber blocks. Fungal hyphae covered the solid wood blocks and the fiber cubes, but very little weight loss was detected. This shows that acetylation is not toxic to the fungus.

Combining Tables 1 and 2, the data shows that if the EMC is below about $6 \%$, there is no attack by both the brown- and white- rot fungus. Griffin reported that decay fungi are most active when the wood moisture content is between $40 \%$ and $85 \%$ moisture content [4]. In 1960, Stamm and Baechler reported that a moisture content above $20 \%$ is necessary for fungal attack [5].

Table 1: Acetyl content and equilibrium moisture content of pine wood and pine fiber.

\begin{tabular}{|c|c|c|c|c|}
\hline & Acetyl* (\%) & EMC (\%) & Acetyl (\%) & 18.6 \\
\hline Pine wood & 1.7 & 19.7 & 23.7 & 6.3 \\
\hline Asplund fiber & 1.4 & 21.2 & 24.1 & 2.3 \\
\hline Masonite fiber & 1.3 & 22.7 & 2.5 \\
\hline
\end{tabular}

*Southern yellow pine naturally contains $0.8-1.9 \%$ acetyl.

Table 2: Weight loss in ASTM D 1413 standard soil block test on control and acetylated southern pine wood and fiber.

\begin{tabular}{|c|c|c|c|c|c|c|}
\hline & Acetyl* $^{*}(\%)$ & Gloeophyllum Trabeum (\%) & Trametes Versicolor (\%) & Acetyl (\%) & $\begin{array}{l}\text { Gloeophyllum } \\
\text { Trabeum (\%) }\end{array}$ & $\begin{array}{c}\text { Trametes } \\
\text { Versicolor (\%) }\end{array}$ \\
\hline Pine wood & 1.7 & 61.5 & 8.7 & 18.6 & $>2$ & $>2$ \\
\hline Asplund fiber & 1.4 & 57.3 & 6.2 & 23.7 & $>2$ & $>2$ \\
\hline Masonite fiber & 1.3 & 59.8 & 7.4 & 24.1 & $>2$ & $>2$ \\
\hline
\end{tabular}

*Southern yellow pine naturally contains $0.8-1.9 \%$ acetyl. 


\section{Conclusion}

Reducing solid pine to fiber using an Asplund Defibrator or Masonite exploder was done several times and the resulting fiber was both consistent, uniform, predictable and reproducible. Acetylation of this fiber results in fiber that is stable and durable. The fiber can be combined with a thermosetting or thermoplastic matrix to produce a wide variety of building materials both structural and non-structural. These composite products are consistent, uniform, predictable, reproduceable, stable and durable.

\section{Acknowledgement}

None.

\section{Conflict of Interest}

No conflict of interest.

\section{References}

1. Rowell RM (2006) Acetylation of wood: A journey from analytical technique to commercial reality. Forest Products Journal 56(9): 4-12.

2. Beckers EPJ, Bongers HPM, Zee ME, Sander C (2003) Acetyl content determination using different analytical techniques. In: Proceedings of the first European Conference on Wood Modification, Ghent, Belgium, Van Acker J, Hill CAS (eds), pp. 83-101.

3. (1976) ASTMD1413 ASTM Standard Method of Testing Wood Preservatives by Laboratory Soil-Block Cultures; American Society for Testing and Materials: West Conshohocken, PA, USA.

4. Griffin D (1977) Water potential and wood-decay fungi. Annu Rev Phytopathol 15: 319-329.

5. Stamm AJ, Baecher RH (1960) Decay resistance and dimensional stability of five modified woods. Forest Products Journal 10(1): 22-26. 